\title{
Cascaded multilevel inverter based STATCOM with power factor correction feature
}

\begin{abstract}
The paper investigates the STATCOM system based on five-level cascaded inverter controlled using carrier-based pulse width modulation (CB-PWM) technique. In this work, the STATCOM is controlled to provide only the reactive power compensation at the point of common coupling (PCC) when an RL load is connected to the power system at different lagging power factors. The rotating switching scheme is employed for the DC link voltage balancing while the phase angle control scheme is used in the STATCOM main system. A new current reference control method is proposed in this work and the effectiveness and the theoretical prediction of the proposed approach for different loading conditions is validated through simulation studies using MATLAB SIMULINK software package.
\end{abstract}

Keyword: Cascade multilevel inverter (CMI); Carrier based pulse width modulation (CBPWM); Flexible AC transmission systems (FACTS); Static synchronous compensator (STATCOM); Voltage source converter (VSC) 